\title{
Prolonged ozone exposure in an allergic airway disease model: Adaptation of airway responsiveness and airway remodeling An-Soo Jang*3, Inseon-S Choi ${ }^{1}$, Jae-Hyuk Lee ${ }^{2}$, Chang-Soo Park ${ }^{2}$ and Choon- Sik Park ${ }^{3}$
}

Address: ${ }^{1}$ Department of Internal Medicine, Chonnam National University Medical School, Gwangju, Republic of Korea, ${ }^{2}$ Pathology, Chonnam National University Medical School, Gwangju, Republic of Korea and ${ }^{3}$ Department of Internal Medicine, Soonchunhyang University Hospital, Bucheon, Gwangju, Republic of Korea

Email: An-Soo Jang* - jas877@schbc.ac.kr; Inseon-S Choi - ischoi@chonnam.ac.kr; Jae-Hyuk Lee - jhlee@chonnam.ac.kr; ChangSoo Park-cspark@chonnam.ac.kr; Choon-Sik Park-mdcspark@unitel.co.kr

* Corresponding author

Published: 13 February 2006

Respiratory Research 2006, 7:24 doi:10.1 186/1465-992I-7-24

This article is available from: http://respiratory-research.com/content/7/I/24

(C) 2006 Jang et al; licensee BioMed Central Ltd.

This is an Open Access article distributed under the terms of the Creative Commons Attribution License (http://creativecommons.org/licenses/by/2.0), which permits unrestricted use, distribution, and reproduction in any medium, provided the original work is properly cited.
Received: 30 September 2005

Accepted: 13 February 2006

\begin{abstract}
Background: Short-term exposure to high concentrations of ozone has been shown to increase airway hyper-responsiveness (AHR). Because the changes in AHR and airway inflammation and structure after chronic ozone exposure need to be determined, the goal of this study was to investigate these effects in a murine model of allergic airway disease.

Methods: We exposed BALB/c mice to 2 ppm ozone for 4, 8, and 12 weeks. We measured the enhanced pause (Penh) to methacholine and performed cell differentials in bronchoalveolar lavage fluid. We quantified the levels of IL-4 and IFN- $\gamma$ in the supernatants of the bronchoalveolar lavage fluids using enzyme immunoassays, and examined the airway architecture under light and electron microscopy.

Results: The groups exposed to ozone for 4, 8, and 12 weeks demonstrated decreased Penh at methacholine concentrations of $12.5,25$, and $50 \mathrm{mg} / \mathrm{ml}$, with a dose-response curve to the right of that for the filtered-air group. Neutrophils and eosinophils increased in the group exposed to ozone for 4 weeks compared to those in the filtered-air group. The ratio of IL-4 to INF- $\gamma$ increased significantly after exposure to ozone for 8 and 12 weeks compared to the ratio for the filtered-air group. The numbers of goblet cells, myofibroblasts, and smooth muscle cells showed timedependent increases in lung tissue sections from the groups exposed to ozone for 4, 8, and 12 weeks.
\end{abstract}

Conclusion: These findings demonstrate that the increase in AHR associated with the allergic airway does not persist during chronic ozone exposure, indicating that airway remodeling and adaptation following repeated exposure to air pollutants can provide protection against AHR.

\section{Introduction}

Asthma is characterized by the presence of a variable airflow limitation, airway hyper-responsiveness (AHR), and airway inflammation [1]. Acute exposure to ozone, which is an important component of the photochemical oxidation products of substrates emitted as air pollution from 
automobile engines [2], decreases pulmonary function, increases AHR, and induces airway inflammation in dogs [3], guinea pigs [4], and humans [5-7]. Chronic airway inflammation is associated with airway remodeling that includes airway wall thickening as a result of inflammatory and structural changes, such as edema; inflammatory cell infiltration; mucous gland hyperplasia; reticular basement membrane thickening; subepithelial fibrosis; vascular smooth muscle cell proliferation, hyperplasia, and hypertrophy; and myofibroblast and goblet cell hypertrophy [8-11]. Airway wall thickening and airway reactivity were inversely associated in patients with asthma, suggesting that airway wall thickening prevents excessive airway narrowing in human subjects in vivo [12].

Interleukin (IL)-4 is key factor contributing to the chronic inflammatory state that characterizes asthma and may be involved in the connective tissue alterations that characterize airway remodeling in asthma. IL-4 can stimulate fibroblasts [13]. Interferon (IFN)- $\gamma$, thought to be deficient in asthma, can antagonize some of the effects of IL4 [14].

The effects of long-term, repeated exposure to ozone on AHR and airway structural changes remain poorly defined. Our underlying hypothesis is that repeated episodes of ozone exposure give rise to some of the remodeling changes associated with asthma, which may in turn be associated with sustained airway dysfunction. The aims of this study were to examine the relationship between ozone exposure and AHR by using barometric wholebody plethysmography (WBP) and to characterize the airway structural changes following a daily 8 -h exposure to 2 ppm ozone for 4, 8, and 12 weeks in a murine model of asthma. Airway inflammation was also assessed by analysis of bronchoalveolar lavage (BAL) fluid.

\section{Methods \\ Mice}

Female BALB/c mice (aged 5 to 6 weeks; DaeMul Laboratories, Daejeon, Korea) known to be high IgE responders were used. The mice were maintained on an ovalbumin (OVA)-free diet and were individually housed in rackmounted stainless steel cages with free access to food and water.

\section{Ovalbumin-induced allergic airway disease model}

An OVA-induced allergic airway disease model of asthma was used with some modification [15]. Briefly, mice were sensitized on days 1 and 14 by intraperitoneal injection with $10 \mu \mathrm{g}$ of grade V OVA (Sigma Chemicals, St. Louis, $\mathrm{MO}$ ) and $1 \mathrm{mg}$ of aluminum potassium sulfate (Sigma Chemicals) in $500 \mu \mathrm{L}$ of saline solution. On days 21 to 23, the mice were challenged by daily exposure $(30 \mathrm{~min})$ to an aerosol of $1 \%(\mathrm{wt} / \mathrm{vol})$ OVA in saline solution. Vehicle control mice were treated with a suspension of aluminum potassium sulfate $(1 \mathrm{mg})$ in saline solution $(500 \mu \mathrm{L})$ and challenged with aerosolized saline solution daily from

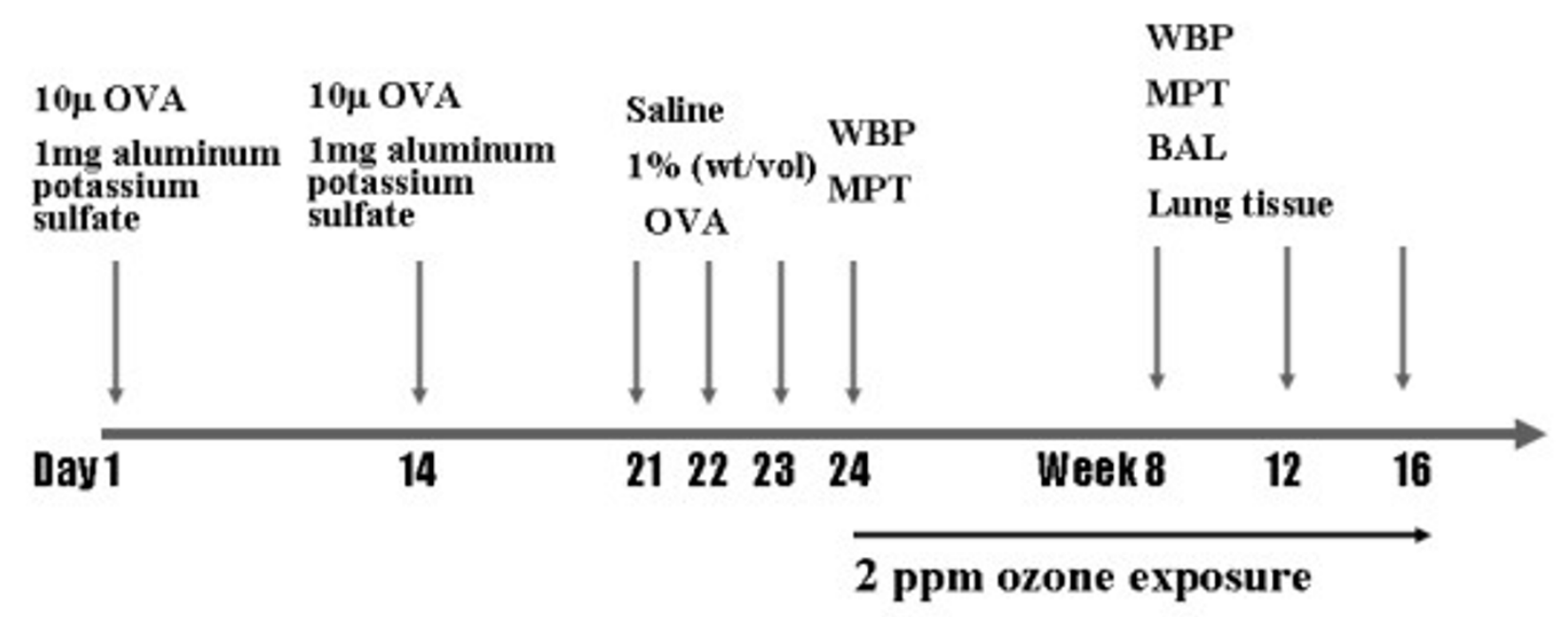

\section{Figure I}

Schematic of the sensitization protocol. Sensitized mice were challenged with I\% (wt/vol) ovalbumin for 30 min on days $21-23$. Groups of mice were exposed to 2 ppm ozone for $8 \mathrm{~h}$ per day for 4, 8, and 12 weeks, respectively. Whole-body plethysmography was performed at 24 days and at 8,12 , and 16 weeks. Broncholalveolar lavage fluid and lung tissue were obtained at 24 days and at 8,12 , and 16 weeks. 


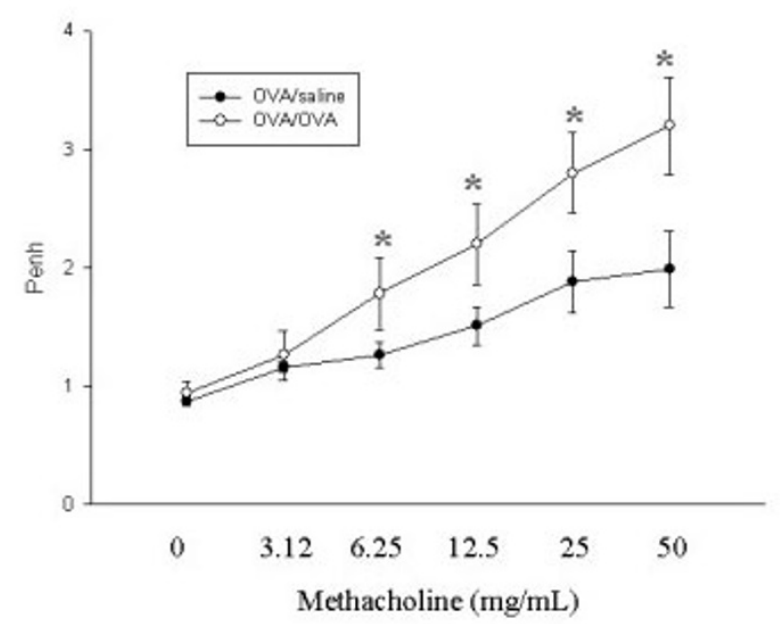

Figure 2

Methacholine-induced airway responses measured by wholebody plethysmography in BALB/c mice challenged with saline and ovalbumin. Values are means $\pm \mathrm{SE} ; n=6$ mice per group. $* p<0.05$ compared to the group exposed to filtered air.

days 21 to 23. Aerosol challenge was conducted on groups of up to 12 mice in a closed chamber attached to an ultrasonic nebulizer (NE-UO7; Omron Corporation, Tokyo, Japan) with an output of $1 \mathrm{~mL} / \mathrm{min}$ and 1 - to $5-\mu \mathrm{m}$ particle size.

\section{Ozone exposure}

The mice housed in whole-body exposure chambers were exposed to ozone concentrations of 2 ppm for 4, 8, and 12 wks ( $n=6$; Fig. 1 ); the ozone doses and exposure times were selected based on our previous study [16]. Ozone was generated with Sander model 50 ozonizers (Sander, Eltze, Germany). The concentration of ozone within the chambers was monitored throughout the exposure with ambient-air ozone motors (model 49 C; Thermo Environmental Instruments Inc., Franklin, MA). The air-sampling probes were placed in the breathing zone of the mice. The mean chamber ozone concentration $( \pm \mathrm{SE})$ during the 8$\mathrm{h}$ exposure period was $1.92 \pm 0.15 \mathrm{ppm}$. The breathing parameter values of spontaneously breathing $\mathrm{BALB} / \mathrm{C}$ mice were determined under standard conditions at room air and temperature.

\section{Determination of airway responsiveness}

Airway responsiveness was measured by barometric plethysmography using whole-body plethysmography (WBP; Buxco, Troy, NY) after ozone exposure, while the animals were awake and breathing spontaneously as a modification of the method described by Hamelmann et al. [17]. Enhanced pause (Penh) to methacholine as meas-

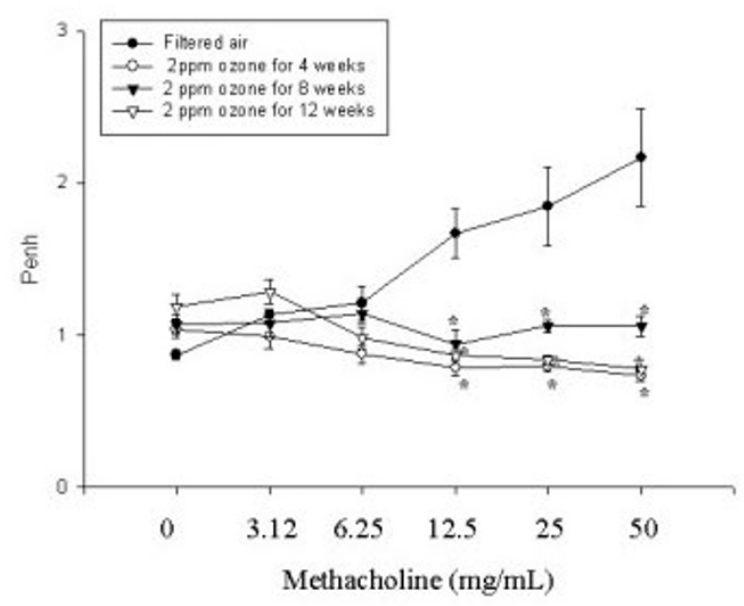

Figure 3

Methacholine-induced airway responses measured by wholebody plethysmography in BALB/c mice exposed to filtered air and to 2 ppm ozone for $8 \mathrm{~h}$ per day for 4,8 , and 12 weeks. Values are means \pm SE; $n=6$ mice per group. ${ }^{*} p<0.05 \mathrm{com}$ pared to the group exposed to filtered air.

ured using barometric plethysmography is a valid indicator of bronchoconstriction in mice and can be used to measure AHR [17-19]. Aerosolized methacholine in increasing concentrations $(2.5-50 \mathrm{mg} / \mathrm{ml})$ was nebulized through an inlet of the main chamber for $3 \mathrm{~min}$.

Bronchoconstriction alters breathing patterns, and changes in the timing of early and late expirations (Pause) and in Penh are the results of alterations in the timing of breathing, as well as the prolongation of the expiratory time. Furthermore, airway constriction increases the thoracic flow asynchronously with the nasal flow, resulting in an increase in the box pressure signal. Penh is an empiric parameter that reflects changes in the waveform of the measured box pressure signal that are a consequence of bronchoconstriction. Before taking readings, the box was calibrated with a rapid injection of $150 \mu \mathrm{l}$ of air into the main chamber. The difference between the pressure in the main chamber of the WBP containing the animal and that in a reference chamber was measured as the box pressure signal, which is caused by the pressure change in the main chamber during the respiratory cycle of the animal. A pneumotachograph with defined resistance in the wall of the main chamber acted as a low-pass filter and allowed thermal compensation. The time constant of the box was determined to be approximately $0.02 \mathrm{~s}$. Mice were placed in the main chamber, and baseline readings were taken and averaged for $3 \mathrm{~min}$. 

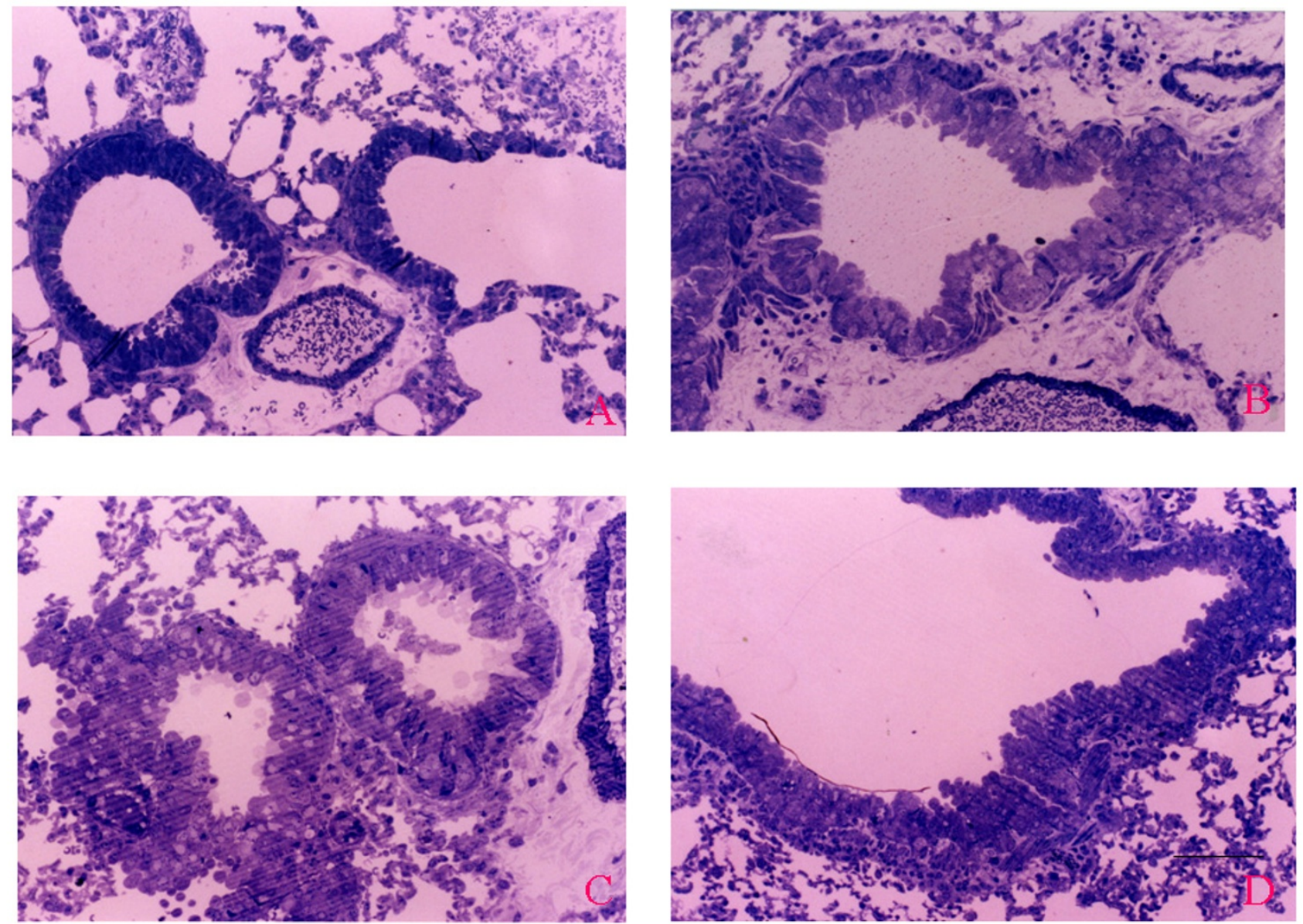

\section{Figure 4}

(A) Bronchioles exposed to filtered air have normal-appearing bronchioles and bronchiolo-alveolar portal and a normal transition from the low columnar epithelium lining the terminal bronchioles to the attenuated epithelium lining the alveoli. (B-D) Bronchioles exposed to 2 ppm ozone for 4, 8, and 12 weeks. (B) Pseudostratified bronchiolar epithelium and goblet cell metaplasia. (C)Markedly increased number of goblet cells. (D) Peribronchiolar collagen deposition and thickened smooth muscle cell coat. Original magnification, $\times 200$. Scale bar $=100 \mu \mathrm{m}$.

\section{BAL fluid preparation and analysis}

BAL was performed immediately after the last measurement of airway responsiveness. The mice were deeply anesthetized with $50 \mathrm{mg} / \mathrm{kg}$ of pentobarbital sodium injected intraperitoneally and were killed by exanguination from the abdominal aorta. The trachea was cannulated with a polyethylene tube through which the lungs were lavaged three times with $1.0 \mathrm{ml}$ of physiological saline ( $4.0 \mathrm{ml}$ total fluid removed). The BAL fluid was filtered through wet gauze $(4 \times 4$ inches). Trypan blue exclusion for viability and total cell count was performed. The BAL fluid was centrifuged at $150 \times g$ for $10 \mathrm{~min}$. The obtained pellet was immediately suspended in $4 \mathrm{ml}$ of physiological saline, and total cell numbers in the BAL fluid were counted in duplicate with a hemocytometer (improved Neubauer counting chamber). A 100- $\mu$ l aliquot was centrifuged in a cytocentrifuge (model 2 Cytospin; Shandon Scientific Co., Pittsburg, PA), and differential cell counts were performed using the centrifuged preparations stained with Diff-quick, counting 500 or more cells for each animal at a magnification of $\times 1000$ (oil immersion).

\section{Cytokine measurement}

The levels of IL- 4 and IFN- $\gamma$ were quantified in the supernatants of BAL fluids by enzyme immunoassays according to the manufacturer's protocol (Endogen Inc., Woburn, $\mathrm{MA}$ ). The sensitivity of the assays was $5 \mathrm{pg} / \mathrm{ml}$. 


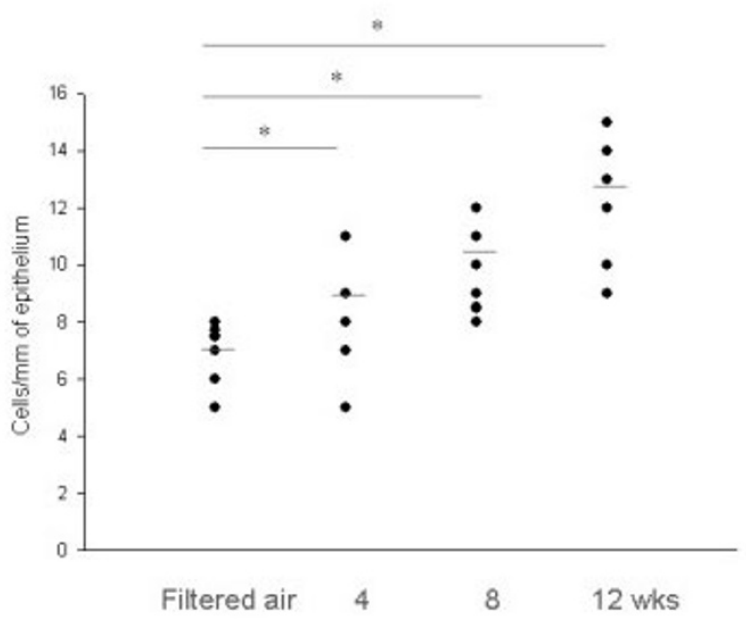

\section{Figure 5}

Goblet cell counts in the epithelium of bronchioles of mice exposed to filtered air and to 2 ppm ozone for 4,8 , and 12 weeks. The results are expressed as number of cells per millimeter of basement membrane. Horizontal bars represent median values. $* p<0.05$ compared to the group exposed to filtered air.

\section{Preparation of lung tissues and morphological analysis}

The mice were euthanized after the final exposure, and the lungs and trachea were filled intratracheally with a fixative ( $0.8 \%$ formalin, $4 \%$ acetic acid) using a ligature around the trachea. The lungs were removed, and lung tissues were fixed with $10 \%$ (vol/vol) neutral buffered formalin. The specimens were dehydrated and embedded in paraffin. For histological examination, $4-\mu \mathrm{m}$ sections of fixed, embedded tissues were cut on a Leica model 2165 rotary microtome (Leica Microsystems, Nussloch, Germany), placed on glass slides, deparaffinized, and stained sequentially with toluidine blue (Richard-Allan Scientific, Kalamazoo, MI). Selected toluidine blue-stained sections were used for measuring epithelial, goblet, and smooth muscle cells providing that the epithelium and submucosa could be easily identified and that the number of epithelial, goblet, and smooth muscle was adequate to allow multiple measurements (i.e., approximately $1 \mathrm{~mm}$ ). Areas of the lung tissue with intact surface epithelium were selected for examination and quantification under a transmission electron microscope (H-7000; Hitachi, Tokyo, Japan). Ultrathin sections were cut, placed on high-transmission, 200-mesh, thin-bar copper grids, and stained with uranyl acetate and lead citrate. Light microscopic quantification was performed at $\times 200$, and electron microscopy was performed at $\times 5000$.
The cells that were counted (e.g., myofibroblasts) were used as evidence of airway remodeling rather than inflammation in a subepithelial zone of the entire transmission electron microscopy section, and the counts were expressed per $0.1 \mathrm{~mm}^{2}$ of tissue. Myofibroblasts were identified by spindle-like projections, dilated rough endoplasmic reticulum, a greatly infolded and crenated nuclear membrane, and bundles of parallel cytoplasmic filaments associated with dense body condensations. The sections were coded and examined under light microscopy in random order by the same observer, who was unaware of the origin of the sections. Intra-observer repeatability was assessed by measuring the same section four times and was expressed as a percentage of the coefficient of variation for the four measurements.

\section{Statistical analysis}

All data were analyzed using SPSS version 7.5 for Windows (SPSS Inc., Chicago, IL). The data are expressed as means \pm SE. For measured variables with a normal distribution, Student's paired $t$-test was used to compare paired data. For variables that did not have a normal distribution, the Mann-Whitney U-test was used for comparisons. Differences with $p$-values less than $5 \%$ were regarded as statistically significant.

\section{Results}

The OVA-exposed group demonstrated significantly increased Penh at methacholine concentrations of 6.25 , $12.5,25$, and $50 \mathrm{mg} / \mathrm{ml}$ compared to that of the salineexposed group (Fig. 2). The ozone-exposed group demonstrated significantly decreased Penh at methacholine concentrations of $12.5,25,50 \mathrm{mg} / \mathrm{ml}$ compared to that of the filtered-air group (Fig. 3). We did not observe any differences in inflammatory cells or the levels of cytokines in the BAL fluids, or any changes in airway remodeling among the groups exposed to filtered air for 4, 8, and 12 weeks (data not shown). Therefore, we used the data for the group exposed to filtered air for 4 weeks in the comparisons to the ozone-exposed groups.

The proportions of eosinophils and neutrophils in BAL fluids were significantly higher in the group exposed to ozone for 4 weeks than in the filtered-air group (filteredair group vs. ozone-exposed for 4 vs. 8 vs. 12 weeks: eosinophils, $1.5 \pm 0.28$ vs. $2.5 \pm 0.13$ vs. $1.11 \pm 0.05$ vs. $1.8 \pm$ $0.08 \%$; neutrophils, $2.2 \pm 1.32$ vs. $4.5 \pm 1.02$ vs. $1.9 \pm 1.22$ vs. $2.5 \pm 2.01 \%$, respectively; $p<0.05)$.

The INF- $\gamma$ level decreased significantly after 4, 8, and 12 weeks of ozone exposure compared to that of the filteredair group. The IL-4 level in BAL fluids was not different between any of the ozone-exposed groups and the filtered-air group (filtered-air group vs. ozone-exposed for 4 vs. 8 vs. 12 weeks: IFN- $\gamma, 75.4 \pm 2.57$ vs. $30.3 \pm 9.52$ vs. 

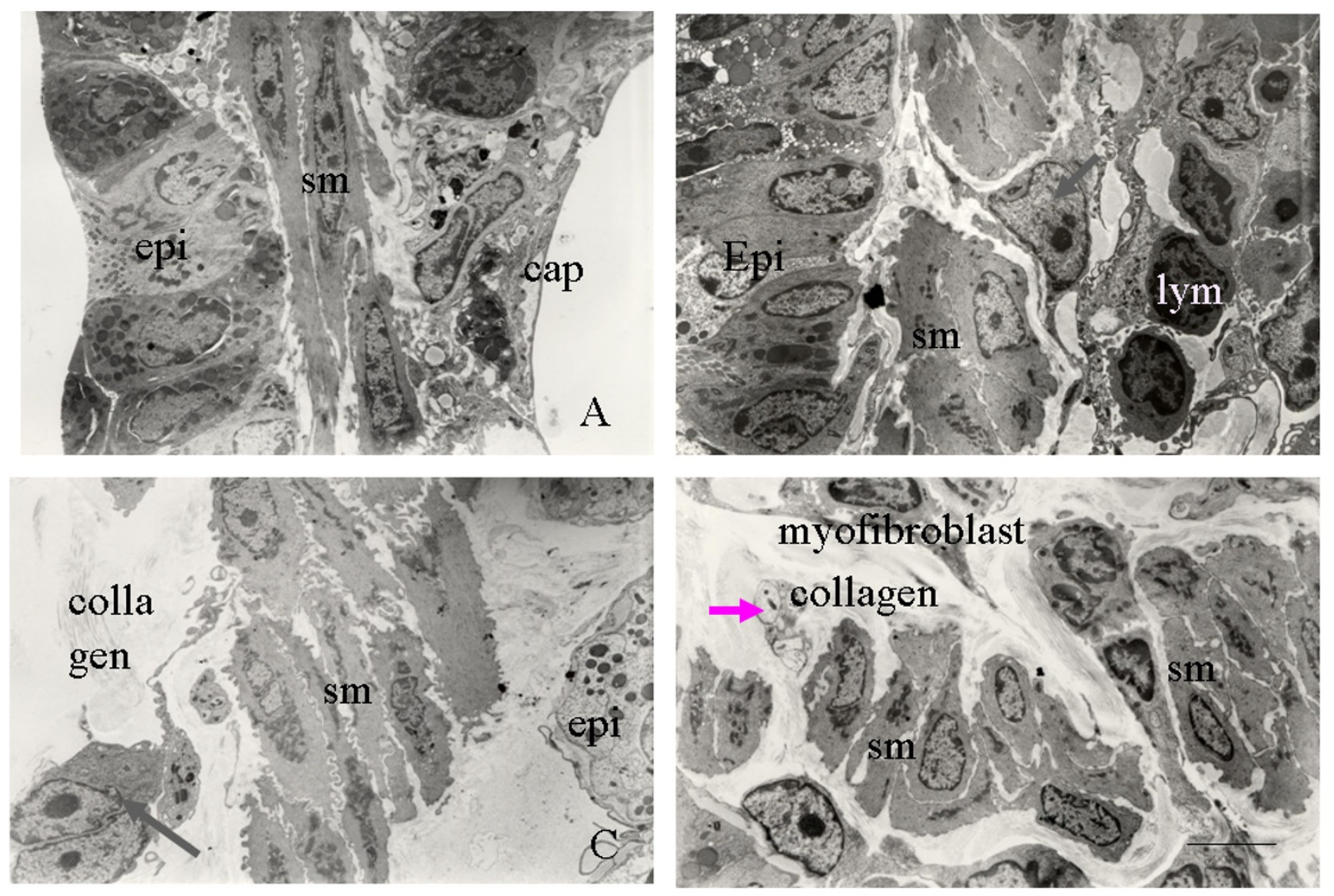

\section{Figure 6}

(A) Transmission electron micrograph of a bronchiole specimen from mice exposed to filtered air showing normal epithelium, smooth muscle, and capillaries. (B-D) Transmission electron micrographs of bronchiole specimens from mice exposed to 2 ppm ozone for 4, 8, and 12 weeks showing (B) hypertrophied smooth muscle cells (sm), a few infiltrating lymphocytes (lym), and myofibroblasts (arrow); (C) myofibroblasts (arrow), interstitial deposition of collagen fibers, and increased smooth muscle cell hypertrophy; and (D) disorganized smooth muscle cells, increased deposition of collagen fiber, unmyelinated nerve fiber (arrow), and myofibroblasts. Original magnification, $\times 5000$. Scale bar $=5 \mu \mathrm{m}$.

$64.9 \pm 2.9$ vs. $55.6 \pm 6.64 \mathrm{pg} / \mathrm{ml} ; \mathrm{IL}-4,33.3 \pm 3.27$ vs. 65.1 \pm 2.96 vs. $55.6 \pm 6.64$ vs. $45.9 \pm 5.26 \mathrm{pg} / \mathrm{ml}$, respectively) The ratio of IL- 4 to INF- $\gamma$ increased significantly after 4,8 , and 12 weeks of ozone exposure compared to the ratio of the filtered-air group (filtered-air group vs. ozone-exposed for 4 vs. 8 vs. 12 weeks: $0.43 \pm 0.1$ vs. $3.24 \pm 3.4$ vs. $1.30 \pm$ 0.89 vs. $0.96 \pm 0.38$, respectively; $p<0.05)$. The ozoneexposed groups also demonstrated significantly increased protein levels compared to that of the filtered-air group (filtered-air group vs. ozone-exposed for 4 vs. 8 vs. 12 weeks: $10.07 \pm 0.06$ vs. $14.55 \pm 0.76$ vs. $11.12 \pm 0.03$ vs. $12.05 \pm 0.11 \mu \mathrm{g} / \mu \mathrm{l} ; p<0.01)$.
The development of airway remodeling in the lungs of ozone-exposed mice was assessed by histological examination of toluidine blue-stained sections of lung tissue. The lungs of mice exposed to ozone for 4, 8, and 12 weeks were isolated, and representative $5-\mu \mathrm{m}$ paraffin sections of lung tissue ( $3 \times$ sections every $100 \mu \mathrm{m})$ were examined. The number of goblet cells was significantly greater in the airway epithelium of mice after 4, 8, and 12 weeks of chronic exposure to ozone than after exposure to filtered air (Fig. 4). In addition to the marked increase in goblet cell number, an increased peribronchiolar collagen layer and a thickened smooth muscle coat were observed in the 


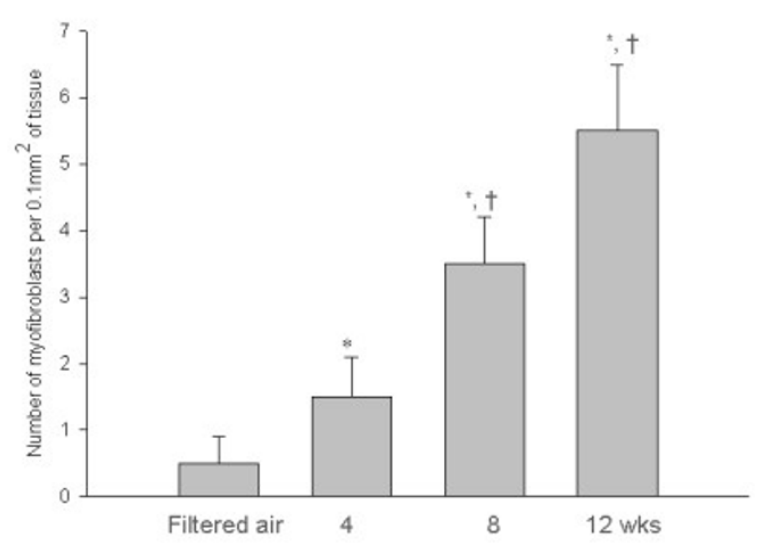

\section{Figure 7}

Mean number of myofibroblasts counted under electron microscopy in the subepithelial zone of specimens from mice exposed to filtered air and to 2 ppm ozone for 4, 8, and 12 weeks. The myofibroblasts comprised cells with elongated projections, dilated rough endoplasmic reticulum, an infolded or crenated nuclear membrane, and bundles of parallel cytoplasmic filaments associated with dense-body condensations. $* p<0.05$ compared to the group exposed to filtered air. $\dagger p$ $<0.05$ compared to the group exposed to ozone for 4 weeks.

lung tissue sections from the ozone-exposed groups (Figs. 4 and $5 ; p<0.05)$. Electron microscopic observations revealed increased collagen fiber deposition, increased smooth muscle cell hypertrophy and hyperplasia, and smooth muscle cell disorganization in the lung tissue sections from the ozone-exposed groups (Fig. 6). The number of myofibroblasts significantly increased in the subepithelial zone after 4, 8, and 12 weeks of chronic exposure to ozone compared to the number in mice exposed to filtered air (Fig. $7 ; p<0.05$ ).

\section{Discussion}

We examined the effects of long-term exposure to ozone on airway remodeling and dysfunction in a mouse model of allergic airway disease. By measuring airway responses to methacholine, we found a decrease in AHR after longterm ozone exposure. We also observed collagen deposition and smooth muscle cell hyperplasia and hypertrophy in mice subjected to long-term ozone exposure. These changes suggest that chronic airway remodeling may be associated with AHR and airway inflammation following long-term exposure to ozone.

Chronic but not brief allergen exposure was associated with a markedly increased amount of extracellular matrix in the subepithelial region of the airway wall and with increased mucin content within the airway epithelium at
4 and 8 weeks after the last allergen challenge [20]. Repeated inflammatory events may contribute to airway remodeling in asthma [21]. Animal studies of allergeninduced AHR have shown that prolonged OVA exposure results in the increased deposition of fibronectin and collagen, which was accompanied by a progressive decrease in AHR, indicating that thickening or stiffening of the airway may be protective against AHR [22,23]. The increase in goblet cell number and in mucus lining the airway may serve a protective function against inhaled toxins and excessive mucosal dehydration [24].

We measured lung function using unrestrained plethysmography, which in conscious mice represents the extreme of noninvasiveness and is highly convenient; however, it provides respiratory measurements that are so tenuously linked to respiratory mechanics that they cannot be considered as meaningful indicators of lung function [25]. In our study using a murine model of asthma, the increase in AHR following OVA sensitization and challenge decreased after repeated exposure to ozone over a period of up to 12 weeks, indicating that structural airway changes can occur as protection against AHR after repeated exposure to air pollutants. Such changes included goblet cell hyperplasia, increased myofibroblast proliferation, increased collagen deposition, and smooth muscle hypertrophy and hyperplasia. Many asthma patients present evidence of residual airway obstruction, which can exist in asymptomatic patients, after antiasthma drugs; this probably represents remodeling. Remodeling may also be important in the pathogenesis of nonspecific AHR, especially the component that reverses slowly or incompletely with inhaled glucocorticosteroid treatment [26].

Airway injury or inflammation caused by air pollutants has been evaluated mainly by the analysis of fluids collected by bronchoalveolar lavage, which is an especially invasive technique totally unsuitable for children. Research in the field of biomarkers is providing new perspectives with the development of noninvasive tests for monitoring inflammation and damage in the deep lung. Our data in a murine model of asthma suggest that repeated exposure to air pollutants can induce airway remodeling and may account for irreversible airway obstruction.

It is necessary to speculate on how various aspects of the remodeling process could contribute to airway dysfunction and nonspecific AHR. IL-4 produced by several cell types, predominantly by Th2 lymphocytes, is believed to contribute to the characteristic inflammatory response in asthmatic airways [27]. IL-4 can modulate the behavior of fibroblasts [13] and may stimulate fibroblast-mediated contraction of extracellular matrix, as in a model of the tis- 
sue remodeling characteristics of fibrotic lesions [28]. The Th2-derived cytokines, IL- 4 and IL-13, can stimulate the production of TGF- $\beta$ in airway epithelial cells but not in lung fibroblasts. IFN- $\gamma$, in contrast, can inhibit TGF- $\beta 2$ release both under basal conditions and following IL- 4 or IL-13 stimulation. The ability of these cytokines to modulate TGF- $\beta$ release may contribute to both normal airway repair and the development of subepithelial fibrosis in asthma [29]. In the present study, the decrease in INF- $\gamma$, the trend toward an increase in IL-4, and the increase in the ratio of IL-4 to INF- $\gamma$ after chronic ozone exposure may contribute to structural airway changes following repeated ozone exposure in a murine model of asthma. Further studies are needed to clarify the potential mechanisms responsible for the AHR decrease in ozone-exposed mice despite the increase in airway smooth muscle mass and airway inflammation, as shown in the present study.

In conclusion, we have demonstrated that the airway physiology and airway structure are altered in a murine model of asthma chronically exposed to ozone. Sustained airway dysfunction was observed after 4 weeks of ozone exposure, and airway remodeling was sustained following 12 weeks of ozone exposure. The observation that airway remodeling persists after the recovery of AHR supports the postulate that structural changes contribute to changes of AHR in mice chronically exposed to ozone.

\section{Acknowledgements}

This work was supported by grant R0I-2003-000-004I-0 From the Basic Research Program of the Korea Science \& Engineering Foundation

\section{References}

I. Busse WW, Lemanske RF Jr: Asthma. N Engl J Med 200I, 344:350-362.

2. Committee of the Environmental and Occupational Health Assembly of the American Thoracic Society: Health effects of outdoor air pollution. Am J Respir Crit Care Med 1996, I 53:3-50.

3. Holtzman MJ, Fabbri LM, O'Byrne PM, Gold BD, Aizawa H, Walters $\mathrm{EH}$, Alpert SE, Nadel JA: Importance of airway inflammation for hyperresponsiveness induced by ozone in dogs. Am Rev Respir Dis 1983, I 27:686-690.

4. Murlas CG, Roum JH: Sequence of pathologic changes in the airway mucosa of guinea pigs during ozone-induced bronchial hyperreactivity. Am Rev Respir Dis I 985, I 3 I:3 |4-20.

5. Basha MA, Gross KB, Gwizdala C], Haidar AH, Popovich J: Bronchoalveolar lavage neutrophilia in asthmatic and healthy volunteers after controlled exposure to ozone and filtered purified air. Chest 1994, 106:1757-1765.

6. Seltzer J, Bigby BG, Stulbarg M, Holtzman MJ, Nadel JA, Ueki IF, Leikauf GD, Goetzl EJ, Boushey HA: O3-induced change in bronchial reactivity to methacholine and airway inflammation in humans. J Appl Physiol 1986, 60:1321-1326.

7. Koren HS, Devlin RB, Graham DE, Mann R, McGee MP, Horstman DH, Kozumbo WJ, Becker S, House DE, McDonnell WF: Ozoneinduced inflammation in the lower airways of human subjects. Am Rev Respir Dis 1989, 139:407-4I5.

8. Jeffery PK: Remodelling in asthma and chronic obstructive lung disease. Am J Respir Crit Care Med 200I, I64:s28-s38.

9. Beckett PA, Howarth PH: Pharmacotherapy and airway remodeling in asthma? Thorax 2003, 58:163-174.

10. Elias JA, Zhu Z, Chupp G, Homer RJ: Airway remodeling in asthma. J Clin Invest 1999, I04:1001-1006.
II. Roche WR, Beasley R, Williams JH, Holgate ST: Subepthelial fibrosis in the bronchi of asthmatics. Lancet 1989, I:520-524.

12. Niimi A, Matsumoto H, Takemura M, Ueda T, Chin K, Mishima M: Relationship of airway wall thickness to airway sensitivity and airway reactivity in asthma. Am J Respir Crit Care Med 2003, 1 68:983-988.

13. Doucet C, Brouty-Boye D, Pottin-Clemenceau C, Canonica GW, Jasmin C, Azzarone B: Interleukin (IL)-4 and ILOI 3 act on human lung fibroblasts. J Clin Invest 1998, I 0 I:2129-2 I 39.

14. Cohn L, Herrick C, Niu N, Homer R, Bottomly K: IL-4 promotes airway eosinophilia by suppressing IFN-gamma production: defining a novel role for IFN gamma in the regulation of allergic airway inflammation. J Immunol 2000, I 66:2760-2767.

I5. Brusselle GG, Kips JC, Tavernier JH, van der Heyden JG, Cuvelier CA, Pauwels RA, Bluethmann $\mathrm{H}$ : Attenuation of allergic airway inflammation in IL-4 deficient mice. Clin Exp Allergy 1994, 24:73-80.

16. Jang AS, Choi IS, Kim SW, Song BC, Yeum CH, Jung JY: Airway obstruction after acute ozone exposure in $B A L B / c$ mice using barometric plethysmography. Kor J Intern Med 2003, 18: $1-5$.

17. Hamelmann E, Schwarze J, Takeda K, Oshiba A, Larsen GL, Irvin CG, Gelfand EW: Noninvasive measurement of airway responsiveness in allergic mice using barometric plethysmography. Am J Respir Crit Care Med 1997, I 56:766-775.

18. Johanson WG Jr, Pierce AK: A noninvasive technique for measurement of airway conductance in small animals. J Appl Physiol 1971, 30:146-150.

19. Pennock BE, Cox CP, Rogers RM, Cain WA, Wells JH: A noninvasive technique for measurement of changes in specific airway resistance. J Appl Physiol 1979, 46:399-406.

20. Leigh R, Ellia R, Wattie J, Southam DS, de Hoogh M, Gauldie J, O'Byrne PM, Inman MD: Dysfunction and remodeling of the mouse airway persist agter resolution of acute allergeninduced airway inflammation. Am J Respir Crit Care Med 2002, 27:526-535.

21. Temelkovski J, Hogan SP, Shepherd DP, Foster PS, Kumar RK: An improved murine model of asthma: selective airway inflammation, epithelial lesions and increased methacholine responsiveness following chronic exposure to aerosolized allergen. Thorax 1998, 53:849-856.

22. Palmans E, Kips JC, Pauwels RA: Prolonged allergen exposure induces structural airway changes in sensitized rats. $A m J$ Respir Crit Care Med 2000, 16 1:627-635.

23. Vanacker NJ, Palmans E, Pauwels RA, Kips JC: Fluticasone inhibits the progression of allergen-induced structural airway changes. Clin Exp Allergy 2002, 32:914-920.

24. McParland BE, Macklem PT, Pare PD: Airway hyperresponsiveness: From molecules to bedside invited review: airway wall remodeling: friend or foe? I Appl Physiol 2003, 95:426-434.

25. Bates $\mathrm{JH}$, Irvin CG: Measuring lung function in mice: the phenotyping uncertainty principle. J Appl Physiol 2003, 94: I297-1306.

26. Kips JA, Pauwels RA: Airway wall remodeling: does it occur and what does it mean? Clin Exp Allergy 1999, 29: I457-I466.

27. Abbas AK, Murphy KM, Sher A: Functional diversity of helper T lymphocytes. Nature 1996, 383:787-793.

28. Postlethwaite AE, Seyer JM: Fibroblast chemotaxis induction by human recombinant interleukin-4. J Clin Invest I99I, 87:2|47-2I52.

29. Wen FQ, Kohyama T, Liu X, Zhu YK, Wang H, Kim HJ, Kobayashi T, Abe S, Spurzem JR, Rennard SI: Interleukin-4 and interleukin- I 3enhanced transforming growth factor-beta2 production in cultured human bronchial epithelial cells is attenuated by interferon-gamma. Am J Respir Cell Mol Biol 2002, 26:484-490. 